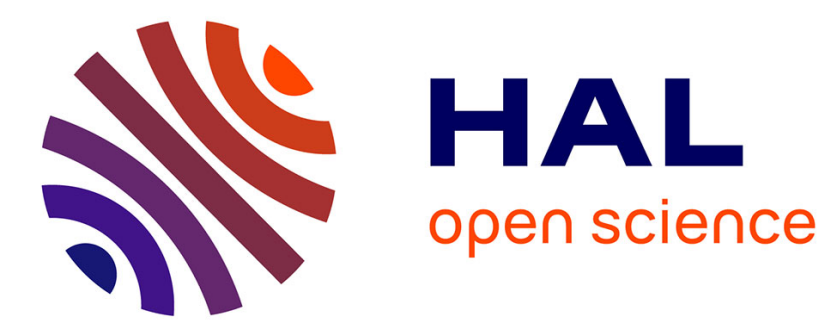

\title{
Referring to states and events
}

Katharina Haude

\section{To cite this version:}

Katharina Haude. Referring to states and events: subordination in Movima. van Gijn, Rik, Katharina Haude and Pieter Muysken. Subordination in South American languages, John Benjamins, pp.141168, 2011. halshs-00671204

\section{HAL Id: halshs-00671204 https://shs.hal.science/halshs-00671204}

Submitted on 16 Feb 2012

HAL is a multi-disciplinary open access archive for the deposit and dissemination of scientific research documents, whether they are published or not. The documents may come from teaching and research institutions in France or abroad, or from public or private research centers.
L'archive ouverte pluridisciplinaire HAL, est destinée au dépôt et à la diffusion de documents scientifiques de niveau recherche, publiés ou non, émanant des établissements d'enseignement et de recherche français ou étrangers, des laboratoires publics ou privés. 


\title{
Referring to states and events Subordination in Movima
}

\author{
Katharina Haude \\ Universität zu Köln
}

Complement and adverbial clauses in Movima (unclassified, Bolivia) are referential phrases that function as main-clause arguments or adjuncts. Unlike main clauses, they are consistently overtly marked for person, tense, and lexical aspect. The reason for this typologically unusual property is that the referential phrases representing subordinate clauses are obligatorily possessed, that their predicates are derived by morphemes that distinguish between events and states, and that their determiner marks temporal deixis. Subordinate clauses therefore seem to display more finiteness features than main clauses, which is partly due to the cross-linguistically common referential character of subordinate clauses combined with the peculiar referential properties of Movima determiners and the low noun-verb distinction.

Keywords: Movima, subordination, nominalization, lexical categories, nominal tense, finiteness

\section{Introduction ${ }^{1}$}

In Movima, an unclassified, endangered language of lowland Bolivia, complement and adverbial clauses have the form of referential phrases. The subordinate predicate is morphologically marked and preceded by an article. It is marked for person in the same way as a possessed noun. All these features hint at a nominalization process, which is common for subordination cross-linguistically (see e.g. Horie 2001) and have their functional explanation in the fact that subordinate events are conceptualized as things rather than processes (see Cristofaro 2003).

However, despite their referential character, Movima complement and adverbial clauses show some properties which are normally considered indicators of finiteness (cf. Nikolaeva 2007), but which are not marked on main-clause predicates: while lexical aspect is not morphologically marked

\footnotetext{
${ }^{1}$ The article was prepared within the Movima documentation project funded by the DobeS programme of the Volkswagen Foundation, during which also part of the data were collected. I wish to thank the Movima speakers who shared their knowledge with me. Acknowledgements for comments on a previous version of this paper are due to Rik van Gijn, Pieter Muysken, Sonia Cristofaro and Francesc Queixalós. All shortcomings and mistakes are my own responsibility.
} 
on main-clause predicates, there are two types of subordinate derivation, suffixation and reduplication, which overtly distinguish between events and states; tense is not obligatorily encoded on main-clause predicates, but the deictic properties of the article locate the subordinate event in time; person, not obligatorily marked on intransitive main predicates, is overtly encoded on all predicates of complement and adverbial clauses.

The assumption that the predicates of complement and adverbial clauses are nominalized forms is furthermore contradicted by the fact that morphological marking is not a necessary requirement for a verb to occur inside a referential phrase (RP): unmarked verbs can also occur inside a RP. RPs containing the morphologically marked, subordinate predicates, refer to states or events, whereas RPs containing underived verbs refer to event participants. Therefore, by denoting states and events, the seemingly nominalized forms show more semantic features that are usually associated with verbs than underived verbs in Movima.

This paper is divided into two parts. The first part (sections 2-4) introduces the most relevant features of Movima syntax, such as the basic structure of main clauses and main-clause predicates (Section 2), the structure of nominal constituents (3), and the noun-verb distinction (4). The second part (Section 5) describes subordinate clauses. Section 5.1 provides a brief account of the functions of subordinate clauses. Sections 5.2-5.4 discuss the characteristics of the subordinate predicate, such as subordinate derivation (5.2), argument structure (5.3), and voice marking (5.4). Section 5.5 describes the tense-marking effect of the article in subordinate clauses. The findings are summed up in Section 6.

\section{Basic main clause structure}

\subsection{The major components of main clauses}

Movima clauses are typically predicate initial. Intransitive clauses may contain maximally one overt argument expression (whose realization is not grammatically obligatory), transitive clauses may contain two (only one of whch is obligatorily realized). Additionally, there can be one or more adjuncts. Arguments and adjuncts consist of a pronoun or a referential phrase (RP). Adjuncts are marked as oblique by the prefix $n$ - $(n V$ - before consonants) on the pronoun or article. Example (1) illustrates an intransitive, example (2) a transitive clause; note the locative adjunct nas towa:net 'onto the path' in (1). Since only RPs are relevant for the 
description of subordination, the examples given here contain only RP arguments. $^{2}$

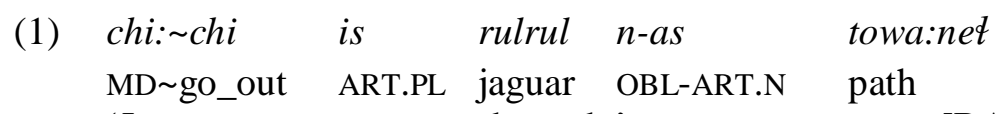

'Jaguars come out onto the path.'

[BAS tx 212]

(2)
man $\langle a>y e=i s \quad$ pa:ko
meet $\langle$ DR $>=$ ART.PL $\operatorname{dog}$
$\begin{array}{ll}\text { os } & \text { rulrul } \\ \text { ART.N.PST } & \text { jaguar }\end{array}$

'The dogs found a jaguar.'

[EAO Tigre y perro 003]

The predicate is typically a verb, as in the above examples, but it can also be a noun, as in (3), or a demonstrative, as in (4). As we will see (Section 3.2), RPs can also contain verbs instead of nouns.

(3)

$\begin{array}{lllll}\text { tomo:re } & \text { is } & e: t a=i s & \text { ney } & \text { wu'tu } \\ \text { tomore } & \text { ART.PL name=ART.PL } & \text { here pot }\end{array}$

'The name of those pots was tomore.'

[HRR tx 265]

$\begin{array}{clcl}\text { (4) koro' } & \text { kos } & \text { lavanderiya } & \text { ney } \\ \text { DEM } & \text { ART.N.AB } & \text { laundry } & \text { here }\end{array}$

'There is a laundry here (in the village).' [Agua sucia 006]

\subsection{Argument encoding and alignment}

The two arguments of a transitive clause are best characterized by their constituency properties (see Haude 2006: 259ff.), one being internal, the other external to the predicate phrase. The internal argument (cf. =is pa:ko in (2)) has the property of being obligatorily realized by a constituent that is "internally" cliticized to the predicate (causing stress shift, among other things, and represented by an equals sign). The absence of an internally cliticized constituent from a bivalent predicate indicates the first person singular.
(5) sal-na=Ø
look_for $=1 \mathrm{SG}$
'I look for (you/him/her/it/them).'

2 Articles are an obligatory part of the referential phrase and do not distinguish between definite and indefinite reference (see 3.1). The English translations of Movima referential phrases therefore only reflect my contextbased intuitions. 
The external argument of a transitive clause (cf. os rulrul in (2)), which has the same formal and behavioural properties as the single argument of an intransitive clause (cf. is rulrul in (1)), is not obligatorily realized, not cliticized when represented by a RP and, when represented by a pronoun, cliticized in a way that does not involve a stress shift. This type of "external cliticization" is represented by a double dash, as illustrated in (6):

(6) pasit-na=is--kas

unfold-DR=3PL--OBV.3N

'They unfolded it.'

[GB Ganado 009]

The representation of the arguments in a transitive clause as either external or internal to the predicate phrase is basically determined by a referential hierarchy, which includes deictic, semantic and pragmatic features (see Haude 2009b and Haude 2010a); basically, its structure is $1>2>3$ topic (given) > 3 nontopic (new). The RP with the higher-ranking referent is the internal, the RP with the lower-ranking the external argument. Since it is not easy to find uncontroversial labels for the grammatical relations in Movima, and since the constituency properties of the arguments are based on a referential hierarchy, I label the internal argument, which refers to the higher-ranking participant, Proximate Argument (PROX), and the external argument which refers to the lower-ranking participant, Obviate Argument $(\mathrm{OBV}) .^{3}$

\subsection{Verbal voice marking}

Participant roles (actor and undergoer) are indicated through direct and inverse marking on the predicate. Direct marking, illustrated in (7), indicates that PROX is the actor and OBV the undergoer; inverse marking, illustrated in (8), indicates the reversed situation. I subsume direct and inverse under the category "voice" because they indicate the participant roles of the core arguments and because they belong to a paradigm of intransitive verb suffixes with a similar function (see Haude 2006: 323 and 5.4 below).

${ }^{3} \mathrm{Cf}$. Bickel in press. These terms, although originally borrowed from the Algonquianist tradition, are to be understood as labels only, indicating that the system is primarily based on referential properties of the arguments rather than on semantic roles. Labels such as "internal/external", "object/subject", "first/second argument" etc., are misleading because of their traditional definitions, especially in view of the fact that in Movima, the referentially low argument has the higher syntactic status (see Haude 2009b, Haude 2010a). 
In main-clause predicates, the inverse voice is invariably marked by the suffix -kay, as in (8) above. Direct is either marked by the suffix -na, as in (7) above, or by the base-internal affix - $a$-. The allomorph - $a$ - appears when the verbal base is morphologically complex and the root has the shape CVC, and is represented as an infix $\langle a\rangle$ on synchronically unanalyzable bases, as in (2) above; ${ }^{4}$ the suffix $-n a$ occurs in all other environments (see Haude 2006: 324f.).

Main-clause verbal predicates that contain neither direct nor inverse marking are monovalent, i.e., they form the predicate of an intransitive clause and may take only one core argument (cf. (1) above). Example (9) illustrates the verb kaykay 'eat', which contains reduplicative middle marking (see Haude 2006: 345ff.), and whose patient can only be expressed as an oblique argument; the verb ratpite:te 'tear (at)' in (10) is marked by the intransitive voice suffix -ete (see Haude 2006: 330f.). The verb ya:lo:we 'drink' in (11) can be identified as monovalent simply due to the absence of direct or inverse marking.

(9)

$\begin{array}{lc}\text { kay kay is } & \text { tochik-mo } \\ \text { MD eat } & \text { ART.PL } \\ * \ldots \quad \text { is } & \text { aro:so } \\ \quad \text { ART.PL } & \text { rice }\end{array}$

'The chicks eat (the) rice.'

\section{n-is aro:so}

small-BE.bird

OBL-ART.PLrice $\ldots$

[e]

(10) rat-pit-e:te $\boldsymbol{n}$-is kade:na

tear-BE.half-AGT OBL-ART.PL chain

'(It) tore its chain.'

[EGA Cazando 147]

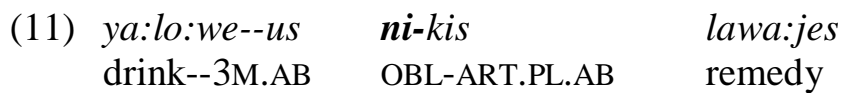

'He drinks a remedy.'

[EGA Dialogue 049]

The fact that the OBV argument in a transitive clause has the same formal properties as the single argument of an intransitive clause implies that direct

${ }^{4}$ In (2), the morpheme -ye can synchronically be identified as the class marker for 'person', but it seems to be lexicalized together with the root. 
transitive clauses, where OBV is the undergoer (see (7)), pattern ergatively, and inverse transitive clauses, where OBV is the actor (see (8)), pattern accusatively. We will see in 5.3 that subordinate clauses pattern in the opposite way: due to the possessor-like encoding of the single argument of the intransitive clause, this argument is encoded like PROX and not like OBV.

\section{Referential phrases}

An argument or adjunct can be expressed by a pronoun or by a referential phrase (RP). Typically, PROX is a bound pronoun and OBV a RP. Since only RPs are relevant to the discussion of subordination, I will describe only these in more detail here.

\subsection{Articles}

A RP is defined by the fact that it contains a determiner preceding a content word. The determiner can be an article or a demonstrative; in the context of subordination, only articles play a role, which is why we will restrict the discussion to articles. The articles are defined as such because they are forms that cannot occur without a subsequent content word; they do not, however, distinguish between definite and indefinite reference. There are some homophonous pronouns (e.g. the plural pronoun $i s$ for absent entities, which is homophonous with the plural article $i$ s for present entities), but belong to a different paradigm; see Haude 2006: 163f., 139f.).

Articles indicate natural gender (masculine and feminine for humans, neuter for non-human entities), number, presence versus absence, and ongoing versus ceased existence of the referent. The Movima articles are given in Table 1.

@@ Insert Table 1 here

The presential/generic article is used when the entity referred to is present at the speech situation, or when it is an entity which is universally known and whose location is fixed. The absential article is used when the referent is absent from the speech situation; the "past" article is used for entities that have ceased to exist. The three-way distinction is illustrated in (12):

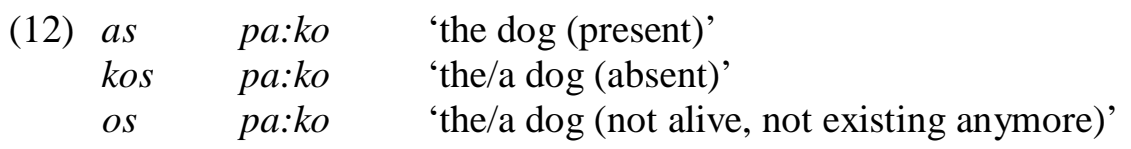


In 5.5 below we will see that in the context of subordination, the three forms of the neuter article are employed to distinguish three temporal, but no spatial categories.

\subsection{Verbs in RPs}

The content word in a RP is typically a noun, as was the case in the examples given so far, but it can also be a verb, as in (13) and (14) below. The referent of a RP containing a bivalent verb is determined by the verb's voice morphology: when the verb is marked as direct, the referent of the RP is the undergoer in a two-participant event, as in (13). When the verb is marked as inverse, the referent is the actor in a two-participant event, as in (14). Since the verbs are bivalent, they retain the PROX argument. In fact, due to the referential status of RPs and the absence of any formal distinction between PROX and a possessor (see 3.3), the morpheme representing PROX can also be interpreted as a possessor, as indicated by the alternative translations in brackets.

$$
\begin{array}{llll}
\text { tatvo:set } & \text { [is } & \text { loj-na }=\text { is } & \text { juyeni] } \\
\text { fall } & \text { ART.PL } & \text { wash-DR=ART.PL } & \text { person }
\end{array}
$$

'The (things that) the people have washed have fallen down.' (lit.:

"The people's washed [things] have fallen down.") [EAO spont.]

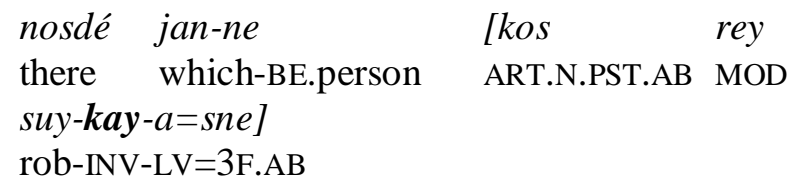

When the verb inside the RP is monovalent, the referent of the RP is the participant in the event that would be expressed as the argument of the verb when it occurs as a predicate. This can be seen in (15) and (16). (In (16), the $\mathrm{RP}$ is modified by a relative clause.)
a. ja<vu: > buk--is
fly<MD >--3PL.AB
'They fly.' 
b. o'o:wa [is ja:<vu: >buk] di' joychoy kay kay audible ART.PL fly<MD > REL probably MD eat $n-i$ '

OBL-3PL

'One could hear the (ones that) flew, which probably ate them.' (about bats eating fruits in a tree at night) [EAO, Wo' ray 002]

(16) a. kat-pit--as

break-BE.middle--ART.N.AB

'It broke/was broken.'

b. vel-na=Ø [os rey kat-pit]

look_at-DR=1SG ART.N.PST MOD break-BE.middle

'I looked at the broken (part), you know.' [ [ERC Sapo 016]

Also when a verb occurs inside a RP, the article indicates referential properties of the event participant, as illustrated by the possessor RP in (17). Here, the article identifies the referent as female and out of existence at the time of speaking.
$\begin{array}{ll}\text { us } & a: k a y-a=\text { [isnos } \\ \text { ART.M older_sibling-LV } & \text { oA }\end{array}$
tikoy-na $=$ as]
ART.M older_sibling-LV=ART.F.PST kill-DR=3N.AB
'the older brother of the (girl) it [i.e. the jaguar] had killed' (lit:
"the older sibling of its (female) killed one")
[HRR_230808]

As we will see in Section 5 below, subordinate phrases can only contain the neuter article, since, unlike verbal RPs, they refer to states and events, i.e. non-human entities.

\subsection{Possessor encoding}

A possessor is encoded in exactly the same way as PROX, i.e. by internal cliticization. This is illustrated in (18) with a bound pronouns and in (19) with a referential phrase encoding the possessor.
(18) as roya=sne
ART.N house $=3$ F.AB
'her house'
(19) as roya=kinos kwe:ya
ART.N house=ART.F.AB woman
'the woman's house'


A first person singular possessor, which cannot be encoded by an enclitic pronoun, is represented by a prenominal marker that replaces the final element $s$ of the article (see Haude 2006: 141f.). ${ }^{5}$

$$
\begin{aligned}
& \text { (20) at ro:ya } \\
& \text { ART.1 house } \\
& \text { 'my house' }
\end{aligned}
$$

A large number of Movima nouns, including kinship and body-part terms, are obligatorily possessed. Here, as in the case with bivalent predicates, the absence of an enclitic person marker implies the first person singular (as on bivalent verbs, the preceding element $t$ is optional). Hence, for instance, i'nes $a y$ 'ku (ART.F aunt) means 'my aunt', and as bo:sa (ART.N arm) means 'my arm'.

\section{Nouns and verbs}

It has become apparent in the preceding sections that verbs and nouns show a large degree of syntactic overlap. The encoding of a possessor is identical to the encoding of PROX in a transitive clause (3.3). Both verbs and nouns can function as predicates (2.1), and both can occur in RPs (3.2); verbs in RPs denote not events, but participants in events, whose role as actor or undergoer is specified by the verbal morphology (see Haude 2010a). ${ }^{6}$

While there is thus a considerable syntactic overlap, nouns and verbs are distinct morphologically. These differences are also rather subtle, since the morphology typical of the different word classes is lacking (see e.g. Schachter 1985): nouns are not morphologically marked for gender, number, or case. Likewise, the typical verbal categories tense, aspect, and mood are encoded by particles and not by verbal morphemes (cf. Haude 2010b).

The morphological distinctions between nouns and verbs basically involve morphemes that can be attached to nouns, but not to verbs. For instance, any noun can, in principle, be marked as possessed by an internally cliticized element (cf. 3.3 above), while verbs can only take an internally cliticized

${ }^{5}$ On bivalent verbs, the proclitic marker of first person is optional.

${ }^{6}$ By going a step further, it can be claimed that also in predicative function, verbs denote event participants rather than events (see Haude 2009a and 2010a for a more detailed discussion). Example (1) might be paraphrased as "(the) jaguars are the ones that come out onto the path", and (2) as "the dog's found one was the/a jaguar". I will not elaborate on this interesting possibility and its implications for the analysis of subordinate clauses here for reasons of space. 
element when they are marked as bivalent by a direct or inverse marker. ${ }^{7}$ The morphemes in (21) can only occur on nouns, but not on verbs $(\mathrm{N}=$ "nominal referent"). ${ }^{8}$

$$
\begin{aligned}
& \text { (21) - tik VBZ 'to carry out the typical action involving N' } \\
& \text {-maj LOC 'to be in/on N' } \\
& \text {-ni PRC 'to be/become N' } \\
& \text { foot } \sim^{9} \text { POSS 'to be owner of } N \text { ' }
\end{aligned}
$$

Furthermore, nouns, but not verbs, undergo reduplication to function as a subordinate predicate, as will be illustrated in 5.2 below. Verbs, in turn, can only take the suffix - wa in subordination. Accordingly, the morphemes in (21) can be considered verbalizers: in subordination, the derived forms take the suffix -wa, as illustrated in (22); they are never reduplicated. ${ }^{10}$

[EAO Cbba 195]

Finally, nouns, but not verbs, can be incorporated into verbal bases, as illustrated in (23) (cf. Haude 2006: 283ff.).
(23) $\begin{array}{lll}\text { wul-a-wa:ris, } & \text { wul-a-saniya, } & \text { wul-a-ma:do } \\ \text { sow-DR-pumpkin } & \text { sow-DR-melon } & \text { sow-DR-bean } \\ \text { '(You) sow pumpkin, (you) sow melon, (you) sow beans.' }\end{array}$

[EAO Chaco I 072]

If the distinction between nouns and especially intransitive verbs is already difficult to make, the identification of adjectives as a distinct word class is even more problematic. Some property-denoting words are more reminiscent of nouns, others are more reminiscent of verbs. Examples of the first type are e.g. tochik 'small', merek 'big', ra:pal 'red' (see Haude 2006: 113 for a more extensive list). They share the property with nouns that they can e.g. be combined with the suffix -tik (e.g. rapal-tik 'to dye something

\footnotetext{
${ }^{7}$ An exception is formed by verbs that contain the suffix - $k a$ d 'immediately', which take an internal clitic even when intransitive (cf. Haude 2006: 426f.).

${ }^{8}$ Like other verbs, when the forms derived with these morphemes occur inside a RP, the RP refers to the event participant.

${ }^{9}$ This reduplication process copies the first iambic foot of the word (Haude 2006: 90f.).

${ }^{10}$ The suffix -tik, however, never cooccurs with the subordination suffix -wa, but is replaced by it (see 5.2 below).
} 
red'). However, they are never found incorporated into verbs, and they cannot constitute the head of a compound.

Other words that might be considered adjectives resemble (or are identical with) verbs with an obligatorily incorporated element (by default the semantically neutral classifier - ra; see Haude 2006: 113f. and 121f.). They are not attested with the nominal morphemes, but can undergo verbal voice marking, as illustrated in (24a) with the direct marker. When unmarked, as in (24b), they denote a state, without any indication of whether the state was brought about by an external agent or not.

(24) a. dol-a:-mi=Ø--a

full-DR-BE.water=1SG--3N

'I fill it with water.'

b. dol-mi--a

full-BE.water--3N

'It (is) full of water.'

These "verblike adjectives" are relevant for the identification of the function of the two subordinating morphemes, to be discussed in 5.2 below.

\section{Subordinate clauses}

\subsection{Types and functions of subordinate clauses}

Three major types of subordinate clauses can be distinguished: relative, complement, and adverbial clauses. The focus of this paper is on the latter two, which constitute referential phrases, consisting minimally of an article and a content word, and which I will subsume under the term "subordinate phrases". ${ }^{11}$ The main formal distinction between subordinate phrases and "normal" referential phrases is that the content word in a subordinate phrase is morphologically derived in a specific way (see 5.2 below).

Complements function either as the single argument of an intransitive clause, as illustrated in (25), or as OBV of a transitive clause, as illustrated in (26) for a direct and in (27) for an inverse main clause.

$$
\begin{array}{lllll}
\text { tas-lo:maj } & \text { [as } & \text { kay-wa=sne } & n \text {-as } & \text { je:mes] } \\
\text { three-BE.time } & \text { ART.N } & \text { eat-EVENT=3F.AB } & \text { OBL-ART.N } & \text { day }
\end{array}
$$

'Three times she eats during the day, three times.' (lit.: "Three times (is) her eating in the day.")

[EAO Asilo 005]

\footnotetext{
${ }^{11}$ Relative clauses, which are not treated here, resemble main clauses; in particular, the predicate is not morphologically derived.
} 
bo ja' ena' kem<a:>ye $=\varnothing \quad$ los jayna

REAS just DUR.std take_for $\langle$ DR $>=1 \mathrm{SG}$ ART.N.PST DSC

kayni-wa='ne]

die-EVENT $=3 \mathrm{~F}$

'Because I was simply thinking that she had already died.' (lit.:

"Because I am simply assuming her past-dying.")

[EAO Esc.Mar. 090]

(27)
joro-poj-kay-a='ne [as
jidan-wa='ne]
sleep-CAUS-INV-LV=3F ART.N
be_full-EVENT $=3 \mathrm{~F}$
'Her being full has made her fall asleep.' [JMH spont.]

Complements also occur in negated clauses. The element kas which introduces negated predicates can be interpreted as a predicate $k a$ 'is not' combined with the determining element $s$ (see Haude 2006: 141f.), which introduces the complement. Consider (28) for a negated verbal and (29) for a negated nominal predicate (see 5.2 on the different derivations). ${ }^{12}$

$$
\begin{array}{ll}
k a[s & k a y-w a=s n e] \\
\text { is_not.DET } & \text { eat-EVENT=3F.AB }
\end{array}
$$

'She didn't eat.' (lit.: 'Her eating was not.') [EAO Flaca 012]

$$
\begin{array}{llll}
k a[s & \text { juye }<\sim n i>n i=a s] & \text { bo } & \text { rulrul--as } \\
\text { is_not.DET } & \text { person }<\sim \mathrm{NMZ}>=3 \mathrm{~N} . \mathrm{AB} & \text { REAS } & \text { jaguar--3N.AB } \\
\text { 'It was not a person, it was a jaguar.' } & & \text { [LYO 250808] }
\end{array}
$$

Adverbial clauses have the form of adjuncts. The oblique prefix $n$-, which marks adjuncts, has a very broad meaning. Oblique RPs containing simple

12 Subordinate clauses, including relative clauses, are negated with the particle loy - reminiscent of the element lol 'without', which is combined with nouns - , as is illustrated in (i) for a complement and in (ii) for an adjunct.

(i) jayna kaw-yemes [as loy joy-wa=y'ti]

DSC much-day ART.N NEG.SUB go-EVENT=1PL

'It's been many days already that we haven't gone (there).'

[EAO Asilo 079]

(ii) $u^{\prime} k o \quad k a y t e-k a y-a=n$ [n-as loy

PRO.M give-INV-LV=2 OBL-ART.N NEG.SUB

terani-wa $=n \quad n$-as tijkarim- $w a=n$ ]

be_ill-EVENT $=2$ OBL-ART.N work-EVENT $=2$

'He [i.e. God] gives you that you don't get ill when you work.'

[EAO Solopaye 008] 
nouns indicate locations, goals, sources, etc. (cf. Haude 2006: 281f.). Likewise, adverbial clauses can be of different types, e.g. temporal, causal, conditional. The most frequent adverbial clauses indicate a temporal relation, as in (30). Note that adverbial clauses often occur clause-initially, and the exact conditions of their occurrence in this position still need to be investigated.

$\begin{array}{lclc}\text { (30) jayna } & \text { [n-os } & \text { ena } & \text { tap-wa }=\varnothing], \\ \text { DSC } & \text { OBL-ART.N.PST } & \text { DUR.std } & \text { bathe-EVENT=1SG } \\ t & \text { tokbaycho } & n \text {-is } & \text { motlo:to } \\ \text { IINTR }^{13} & \text { remember } & \text { OBL-ART.PL earring }\end{array}$

'Then, as I was bathing, I remembered the earrings.'

[EAO Aros II 044]

\subsection{Subordinate derivation: nominalization or lexical aspect?}

The predicate of a subordinate phrase is always overtly morphologically marked. This marking can easily be considered nominalization (as in Haude 2006), since the derived forms usually occur in RPs, ${ }^{14}$ and subordination through nominalization is a common phenomenon cross-linguistically (see e.g. Horie 2001; Noonan 2007; Payne 1997). However, I argue that the factor subordination in Movima shares with nominalizing subordination in other languages is the referential, "thing-denoting" (cf. Christofaro 2003: 284) character induced by the article, while the derivation itself is not nominalization in the strict, morphological sense. First of all, there are no morphological tests for identifying the derived forms as nouns. They cannot be incorporated and cannot take any of the suffixes listed in (21). ${ }^{15}$ It may even be the case that the "nominalizers", rather than marking a lexical category, cancel the entity/participant reading of an underived verb in a RP

${ }^{13}$ First and second person are optionally encoded by an element preceding the head; the markers are distinct from the free pronouns, which can occur additionally (see Haude 2006: 274).

${ }^{14}$ In the few cases in which subordinate phrases are not preceded by an article and can therefore be interpreted as main-clause predicates, they cooccur with an oblique free pronoun in topic position that refers to the time at which the situation takes place:

i) n-asko rey dichi<ye: >ye $=\varnothing \quad$ di:ra OBL-PRO.N.AB MOD child<STATE $>=1 \mathrm{SG}$ still

'By then I was still a child, you see.' (lit.: "At that (was) my being still a child, you see.") [BAS tx 009]

15 The subordination marker - wa can only be followed by bound lexical elements, which derive nouns that again denote concrete entities; e.g. iwani$w a-m-b a$ (talk-EVENT-LN-BR.round) 'telephone'. 
(see 3.2) and to force a state/event reading instead. Therefore, I prefer to speak of subordinate derivation rather than of nominalization.

Subordinate predicates based on verbs are derived by the suffix $-w a$, as shown in (31). ${ }^{16}$ Predicate nominals, in contrast, undergo infixing reduplication of the last CV-segment of the word (see Haude 2006: 84), as shown in (32). The derived forms are obligatorily marked for person by an internal enclitic, i.e. the subordinate phrase has the form of an inalienably possessed RP (see 3.3). Unlike RPs containing underived content words, which refer to entities (when nouns) or event participants (when verbs; see 3.2), subordinate phrases refer to situations, i.e. events or states. (This becomes most apparent when the article is considered, which can only be neuter and marks temporal, not spatial categories; see 5.5).

$$
\begin{aligned}
& \text { a. ya:lo:we--sne } \\
& \text { drink--3F.AB } \\
& \text { 'She drinks/drank.' } \\
& \text { b. isne alkava yey-na=sne } \\
& \text { PRO.F.AB immediately want-DR-3F.AB } \\
& \text { [os ya:lowe-wa=sne] } \\
& \text { ART.N.PST drink-EVENT=3F.AB } \\
& \text { 'Her, she wanted to drink at once.' (lit.: 'She, at once, wants } \\
& \text { her past-drinking.") }
\end{aligned}
$$

(32) a. tolkosya--sne

girl--3F.AB

'She is/was a girl.'

b. dottot--isne [n-os tolkos<ya > ya=sne]

wicked--3F.AB OBL-ART.N.PST girl<STATE $>=3$ F.AB

'When she was a girl, she was wicked.' (lit.: 'She is bad at her past-being a girl.")

[EAO Mala 002]

There are different ways of interpreting the two types of subordinate derivation. One is to see them as depending on the word class, as defined by morphological criteria: verbs receive the suffix $-w a$ and nouns undergo reduplication.

However, another perspective that I wish to propagate here, which is reflected in my glosses of the subordination markers, is that the two derivational processes are considered overt markers of lexical aspect (Aktionsarten): -wa marks events and non-time-stable states, such as the state of being involved in an activity or being at a place ("X-ing" or "being

16 The only exception is formed by subordinate clauses introduced by the particle jan 'that's why', in which predicates are derived by a suffix -na, not identical to the direct marker (see Haude 2006: 474f.). 
at X"), and reduplication marks time-stable, existential states ("being X"). ${ }^{17}$ There are two pieces of evidence for this.

First, like verbs, also nouns can receive the suffix -wa. Unlike reduplication, the suffixation of - $w a$ does not derive a word that denotes the state of being the entity denoted by the noun, but the action typically associated with it, as shown in (33a). This meaning is identical to a denominal verb derived through the suffix -tik (cf. (21) in Section 4), as can be seen in $(33 b)$.

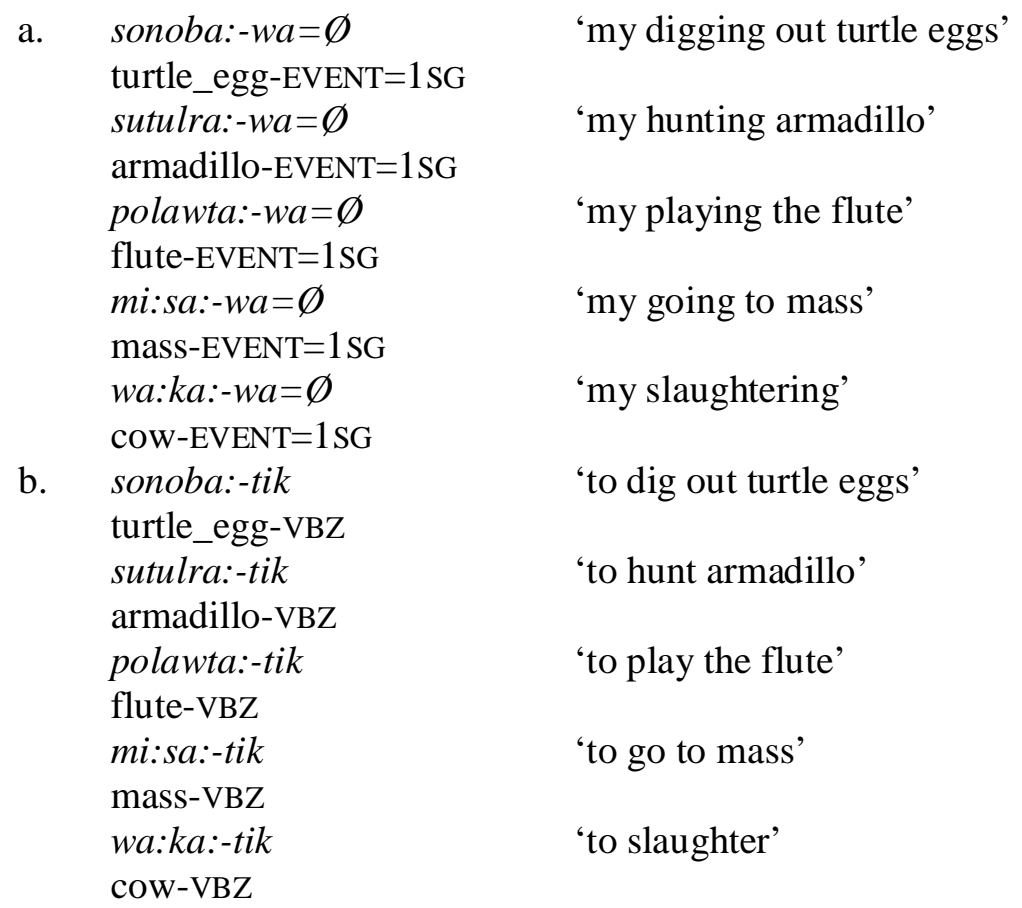

With respect to the interpretation of the forms in (33a), two analyses are possible. It can be claimed that these forms are derived from the verbs in (33b), from which the suffix -tik is dropped in the course of the derivational process. ${ }^{18}$ Alternatively, the suffix -wa itself can be seen as contributing the "event" reading: in the same way as -tik, it derives a word denoting the action typically associated with the entity denoted by the noun. In contrast, reduplication derives a word that denotes the state of being an entity.

${ }^{17}$ Note that -wa can also mark states, albeit not existential ones: it is also attached to words denoting processes and locational states (such as e.g. verbs derived by $-n i$ 'to be/become N' or -maj 'to be at N').

18 Other verbal morphemes are also "dropped" when an additional morpheme is added (see 5.4 below and Haude 2006: 357ff.): for example, the reflexive/reciprocal marker, the middle reduplication, and in some environments, the inverse marker. 
These two analyses of the suffix - wa on nouns, i.e. i) as being attached to a form verbalized through -tik, which is then reduced to zero, or ii) as being attached directly to the bare noun and adding the event reading itself, seem to be equally plausible. However, the evidence that the two types of subordinate derivation indicate lexical aspect (-wa deriving and eventdenoting word) is much stronger when verblike adjectives are taken into account (see Section 4 above). It was shown above (ex. (24)) that a verblike adjective like dolmi 'full of water' denotes a state. In the same way as a noun, an adjective of this type can undergo either suffixation of -wa or reduplication when functioning as a subordinate predicate. Here, the type of derivation clearly marks the aspectual difference between an event, as in (34a), and a state, as in (34b).

$$
\begin{aligned}
& \text { a. n-as dol-mi-wa=a } \\
& \text { OBL-ART.N full-BE.water-EVENT=3N } \\
& \text { 'when it has been filled with water' } \\
& \text { b. n-as dol-<mi } \sim m i=a \\
& \text { OBL-ART.N full-<STATE } \sim \text { BE. water }=3 \mathrm{~N} \\
& \text { 'when it is full of water' }
\end{aligned}
$$

The fact that there can be a direct choice between the two types of subordinate derivation, without any reason to assume a verbalizing zero morpheme, is a further sign that the two types of subordinate derivation have an aspect-marking function, rather than that they depend on lexical class.

Verbs cannot be derived through reduplication. This can be seen as evidence that, even if verbs are interpreted as denoting event participants (see fn. 6), the denotee of a verb is a non-time-stable concept, only existing during the time of the event itself. Possibly as a correlate of this, there is a special suffix $-p a$, which derives agentive nouns which do undergo reduplication in subordination. Consider the difference between a mainclause verb and its subordinate form in (35) and the agentive noun and its subordinate form in (36). ${ }^{19}$

(35) a. tolkara-na=us

rob-DR=3M.AB

'He robs her/him/it/them.'

[e]

$\begin{array}{lll}\text { b. } & n \text {-os } & \text { tolkara-na-wa }=u s \\ & \text { OBL-ART.N.PST } & \text { rob-DR-EVENT=3M.AB }\end{array}$

'when he robbed her/him/it/them'

19 The suffix -pa can also occur on nominal bases, implying the same "action" reading as found with the suffix -tik: rulrul-tik 'to hunt jaguars', rulrul-pa 'a jaguar-hunter'. 


\section{a. tolkara-na:-pa--us}

rob-DR-AG--3M.AB

'He is a thief / he is someone who regularly robs.'

b. n-os tolkara-na-<pa $>$ pa $=u s$

OBL-ART.N.PST rob-DR-<STATE $>\mathrm{AG}=3 \mathrm{M} . \mathrm{AB}$

'when he was a thief / someone who regularly robbed' [e]

The relation between event/state derivation and word-class distinction is a topic for further research: the syntactic flexibility of different words still needs to be investigated in more detail in order to find out whether the type of derivation is based on lexical categories or whether we are dealing with productive aspectual markers. It should be clear, however, that reduplicated subordinate predicates denote existential states, while words suffixed with - $w a$ denote events and non-time-stable states. Thus, independently of the underlying motivations, all subordinate predicates are overtly marked for lexical aspect, something that cannot be said of main-clause predicates.

\subsection{Argument structure and alignment in subordinate phrases}

As was mentioned before, subordinate phrases are obligatorily possessed: the absence of an internally cliticized element indicates the first person singular. This is the case both of bivalent (37) and monovalent subordinate predicates, be they verbal (38) or nominal (39).

$$
\begin{aligned}
& \text { jiram-poj-kay }=\varnothing \quad[\text { os } \quad \text { sit-a-'oj-wa }=\varnothing] \\
& \text { nice-CAUS-INV }=1 \mathrm{SG} \quad \text { ART.N.PST } \quad \text { sew-DR-BE.clothes-EVENT=1SG }
\end{aligned}
$$

$$
\begin{aligned}
& \text { yey- } n a=\varnothing \quad[o s \quad \text { joy-wa }=\varnothing] \\
& \text { want-DR=1SG ART.N.PST go-EVENT }=1 \mathrm{SG}
\end{aligned}
$$

[BAS tx 056]

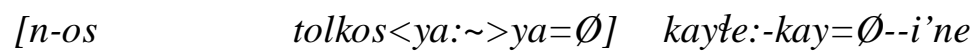

$$
\begin{aligned}
& \text { OBL-ART.N.PST girl<STATE }>=1 \mathrm{SG} \text { give-INV=1SG--3F } \\
& \text { 'When I was a girl, she gave (them) to me.' [EAO Aros 006] }
\end{aligned}
$$

Like transitive main-clause predicates, transitive subordinate phrases can contain two core arguments, which shows that despite the appearance as a possessed RP, subordinate phrases also have clause-like syntactic properties (cf. Comrie and Thompson 1985: 372f.). The encoding of the two arguments in a transitive subordinate clause follows the same principles as in main clauses: the participant that ranks higher in the referential hierarchy is encoded as PROX/possessor, i.e. by an obligatory, internal enclitic. In (40), this is illustrated with the direct, and in (41) with the inverse voice (see 5.4 below on reduplicative inverse marking). 
(40)

$\begin{array}{llll}\text { yey- } n a=\emptyset & {[\text { as }} & \text { visitar-na: }- \text { wa }=\varnothing & \text { kus } \\ \text { want-DR }=1 \mathrm{SG} & \text { ART.N } & \text { visit-DR-EVENT=1SG } & \text { ART.M.AB } \\ \text { alkaka: } y e=\varnothing] & & & \end{array}$

relative $=1 \mathrm{SG}$

'I want to visit my relative.' (lit.: "I want my visiting my relative.") [EAO Visita 047]

(41)
kas
PRO.PL.AB is_not come-EVENT $=3 \mathrm{PL}$
[n-as rey
vel vel-wa=n--is]
INV look_after- EVENT=2--3PL

'They don't come to see you, you know.' (lit.: 'They, their coming for you being seen by them is not.") [EAO In between 090]

Example (42) illustrates multiple subordination: here, the OBV argument of the subordinate phrase is another subordinate phrase (modified by a relative clause) that is transitive and contains two overtly realized arguments.

\begin{tabular}{|c|c|c|c|}
\hline $\begin{array}{l}\text { kaw-ra } \\
\text { much-BE.NTR }\end{array}$ & $\begin{array}{ll}\text { as } & \text { dit-tej-r } \\
\text { ART.N } & \text { heavy-B }\end{array}$ & $\begin{array}{l}\text { anas }-a=n \\
\text { E.breath-AB }\end{array}$ & STR-LV=2 \\
\hline$[n-a s$ & $y e \sim y e y-w a=n$ & [as & $j i: s a-n a-w a=n$ \\
\hline T.N & DR $\sim$ want-EVENT $=2$ & ART.N & make-DR-EVENT=2 \\
\hline$O S$ & $\begin{array}{ll}\text { sot-ra } & d i \\
\text { other-BE.NTR } & \text { REL }\end{array}$ & $\begin{array}{l}\text { dochik } \\
\text { more }\end{array}$ & $\begin{array}{l}\text { merek]] } \\
\text { big }\end{array}$ \\
\hline
\end{tabular}

'And you have a lot of power when you want to make a different thing that is a bit larger.'

[HRR tx 420f.]

Like in a transitive main clause, the OBV of a transitive subordinate phrase can be expressed by a bound pronoun, as in (43), or omitted, as in (44).

$$
\begin{array}{lll}
\text { joychoy } \quad \text { yey-na=sne } & \text { [as } & \\
\text { probably want-DR=3F.AB } & \text { ART.N } & \text { wa:ka] } \\
\text { kay }<a>t e-w a=\text { sne--kus } & \text { ni-kis } & \text { cow } \\
\text { give }<\mathrm{DR}>\text {-EVENT=3F.AB--OBV.3M.AB } & \text { OBL-ART.PL.AB } & \text { cow }
\end{array}
$$

'Probably she wants to give him cattle.' [EAO Patrona 008]

$$
\begin{array}{cllcc}
\text { jayna } & \text { [n-os } & & \text { ma man-wa=us], } & \text { jayna } \\
\text { DSC } & \text { OBL-ART.N.PST } & \text { DR } \sim \text { Shoot-EVENT=3M.AB } & \text { DSC } \\
\text { chi: } \sim \text { chi } & \text { os } & \text { pa: } k o & \\
\text { MD go_out } & \text { ART.N.PST } & \text { dog } &
\end{array}
$$

'Then when he had shot (the jaguar), the dog came out (of the jaguar's grip).'

[EAO Tigre y Perro 022] 
When two third persons are involved, the main-clause PROX is normally also encoded as PROX in the subordinate phrase. When it is the undergoer, the subordinate predicate is marked as inverse, as in (45).

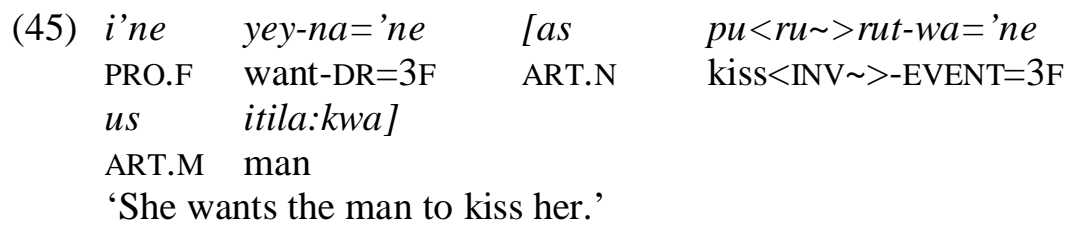

Due to the obligatory encoding of person, the subordinate phrase can be interpreted independently of the main clause: there is no coreferential argument deletion; zero encoding implies the first person singular, as was shown above. This is also clearly apparent in (46), where neither of the arguments in the subordinate phrase are coreferential with the argument of the main clause.
[BAS tx 206]

The subordinate phrase can also help to retrieve a main-clause argument that is not overtly expressed, as in (47) and (48), where both the main clause and the subordinate phrase contain a monovalent predicate. The argument of the main clause needs to be inferred from the context, while the argument of the subordinate phrase is obligatorily overtly encoded.

$$
\begin{array}{lllll}
\text { jayna } & \text { bote-wuktu } & \text { [bo } & \text { os } & \text { dejal-wa=sne }] \\
\text { DSC } & \text { borrow-pan } & \text { REAS } & \text { ART.N.PST } & \text { cook-EVENT=3F.AB }
\end{array}
$$

'Then (she) borrowed pans in order to cook.' (lit.: "Then (she) panborrows for her past-cooking.") [EAO In between 205]

$$
\begin{aligned}
& \text { joy-chet } \quad \text { te } n \text {-os lo-wa='ne nosdé] } \\
& \text { go-R/R } \quad \text { OBL-ART.N.PST dance-EVENT=3F there } \\
& \text { 'She went to dance there.' (lit.: “(She) goes for her past-dancing } \\
& \text { there.”) } \\
& \text { [EAO In between 012] }
\end{aligned}
$$

Thus, in terms of argument encoding, subordinate phrases are not underspecified in comparison to main clauses, as is often the case crosslinguistically (cf. Croft 2003: 216-217). On the contrary: person marking on subordinate predicates is more consistent than on main-clause predicates, because even the single argument of an intransitive clause is obligatorily 
encoded. The unexpressed argument of the main clause can be inferred from the subordinate clause, not vice versa.

As a secondary effect, the fact that in a subordinate phrase, also a monovalent predicate is marked for person by an internal enclitic, implies furthermore that the alignment pattern of subordinate phrases differs from that of main clauses (see 2.2 above). While in main clauses, the argument of an intransitive clause aligns with OBV of a transitive clause, in subordinate phrases, which have the form of possessed RPs, it aligns with PROX, as illustrated in (49) below. Accordingly, a direct transitive subordinate phrase (50b) patterns accusatively, since the actor is encoded like the single argument of an intransitive subordinate phrase (50a); an inverse subordinate phrase $(50 \mathrm{c})$ patterns ergatively, since the undergoer is encoded like the single argument of an intransitive clause. Hence, due to the fact that intransitive subordinate phrases have the form of possessed RPs, the alignment patterns of subordinate phrases are opposite to those of main clauses, presented in 2.2 above. (The reduplicative marking of direct and inverse voice in subordinate phrases is described in the following section.)

(49) a. intransitive:

yey-na $=\varnothing \quad$ [as joy-wa=sne]

want-DR=1SG ART.N go-EVENT=3F.AB

'I want her to go.'

[e]

b. transitive direct

yey-na $=\varnothing \quad$ [as sa sal - wa $=$ sne

want-DR=1SG ART.N DR $\sim$ search-EVENT=3F.AB

kus $\quad a: k a y=\emptyset]$

ART.M.AB older_sibling $=1 \mathrm{SG}$

'I want her to look for my older brother.'

c. transitive inverse

\begin{tabular}{|c|c|c|}
\hline yey-na=Ø & [as & sal $\sim$ sal- $w a=$ sne \\
\hline want $-\mathrm{DR}=1 \mathrm{SG}$ & ART.N & INV $\sim$ search_for-EVENT $=3 \mathrm{~F} . \mathrm{AB}$ \\
\hline kus & $a: k a y=\emptyset]$ & \\
\hline ART.M.AB & older_sibl & $=1 \mathrm{SG}$ \\
\hline
\end{tabular}

Thus, contrary to the expectation raised by the syntactic status of subordinate phrases as RPs, the predicates of subordinate phrases are more "verblike" than underived verbs, not only with respect to the aspectual and temporal features they encode. While, at least inside RPs, it is underived verbs denote event participants rather than events, subordinate predicates can only be interpreted as denoting states and events, which is a prototypical semantic property of verbs (cf. Croft 2003: 185). 


\subsection{Voice marking on subordinate predicates}

Main-clause predicates can be marked with various voice morphemes. The direct and inverse voice markers, which overtly mark all bivalent mainclause predicates, were already introduced in 3 above. Apart from that, there are several morphemes that mark monovalent verbs, on which they indicate the participant role of the single core argument: the "agentive" suffix -ete indicates that the single participant is the agent, the "resultative" suffix - $i$ indicates that it is the undergoer, and the "reflexive/reciprocal" suffix -chet as well as the reduplicative "middle" marker indicate that the single argument expresses agent and undergoer simultaneously.

On subordinate predicates, fewer of these categories are overtly marked than on main-clause predicates. ${ }^{20}$ Of the voice morphemes, only the direct and the agentive marker are overtly expressed everywhere. Inverse marking only occurs under specific morphological conditions. Reflexive/reciprocal and middle are never marked on subordinate predicates. In principle, the absence of a direct or inverse marker indicates that the predicate is intransitive; only in specific contexts (see (58) and (59) below) can an unmarked predicate be identified as bivalent and inverse.

First, consider (50) and (51), which show that reflexive/reciprocal and middle marking are dropped in subordination. Compare the corresponding predicates in the main clause.

$$
\begin{aligned}
& \text { des-chet--us, che [n-os des-wa=us], ..., } \\
& \text { jump-R/R--3M.AB and OBL-ART.N.PST jump-EVENT=3M.AB }
\end{aligned}
$$

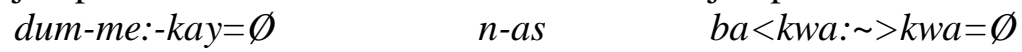

$$
\begin{aligned}
& \text { find-BE.person-INV }=1 \mathrm{SG} \quad \text { OBL-ART.N head }\langle\mathrm{INAL} \sim>=\varnothing
\end{aligned}
$$

'He jumped, and as he jumped (lit.: "in his past jumping"), ..., he hit me against my head.' [EAO Golpearse 032]

(51) $k a^{\prime} d e=[a s \quad$ jayna pat-wa $=i s], \quad$ jayna pat $\sim$ pat end_of=ART.N DSC sprout-EVENT=3PL.AB DSC MD sprout nokopa jayna

like_this DSC

'When they sprout (lit.: "at the end of their sprouting"), then (they) sprout like this.'

[EAO Chaco I 065]

Example (52) shows that the 'agentive' marker -ete is retained (albeit shortened to -et, as always before other suffixes; see Haude 2006: 331).

${ }^{20}$ This is not only the case in subordination: these morphemes are also dropped when other verbal affixes are attached, such as causative -poj and benefactive - $k w a$ (Haude 2006: 357ff.). 


$$
\begin{array}{llll}
{[n-o s} & l a & \text { rey } & \text { pul-et-wa } \left.=y^{\prime} t i\right] \\
\text { OBL-ART.N.PST } & \text { ANT } & \text { again } & \text { sweep-AGT-EVENT=1PL }
\end{array}
$$

'when we last swept'

[EAO Dialogue 006]

Direct is always, inverse only sometimes marked on subordinate predicates. Inverse is either marked by CVC- or base-final reduplication (see Haude 2006: 84ff.), or it is omitted altogether; the direct suffix - na can optionally be replaced by $\mathrm{CV}$-reduplication. All this depends on the morphological properties of the verbal base.

When a verbal base consists of the root alone, the direct allomorph -na is optionally replaced by word-initial CV-reduplication, as shown in (53). In contrast, inverse marking on these bases is obligatorily marked by bimoraic reduplication (CVC or CV: ), as shown in (54).

$$
\begin{aligned}
& \text { a. n-os sal-na:-wa= } \\
& \text { OBL-ART.N.PST search_for-DR-EVENT=1SG } \\
& \sim \text { b. } n \text {-os } \quad s a \sim s a l-w a=\varnothing \\
& \text { OBL-ART.N.PST DR } \sim \text { Search_for-EVENT }=1 \mathrm{SG} \\
& \text { 'when I looked for you/her/him/it/them' }
\end{aligned}
$$

$$
\begin{aligned}
& \text { n-os } \quad \text { sal } \sim \text { sal-wa }=\varnothing \\
& \text { OBL-ART.N.PST INV search_for-EVENT=1SG } \\
& \text { 'when you/she/he/it/they looked for me' } \\
& \text { b. *n-os sal-kay-wa=Ø } \\
& \text { OBL-ART.N.PST search_for-INV-EVENT=1SG }
\end{aligned}
$$

When a verbal base consists of a root with more than one syllable, so that it is marked as direct by the suffix -na (cf. 2.3above on the distribution of -na and $-a-)$, the suffix $-n a$ is always retained on the subordinate predicate, as shown in (55); reduplication is no option here.

$$
\begin{aligned}
& \text { yey-na=n [as ya:lowe-te-na:-wa }=\varnothing \quad n \text {-is } \\
& \text { want-DR=2 ART.N drink-CO-DR-EVENT=1SG OBL-ART.PL } \\
& \text { chi:loj di' pokso] } \\
& \text { provision REL chicha } \\
& \text { 'Do you want me to give (you) to drink of my provisions, which is }
\end{aligned}
$$
chicha?'

[EAO Sueño 103]

The inverse form of a subordinate verb of this type is formed by infixing CV-reduplication (see Haude 2006: 84f.), as shown in (57a). Example (57b) shows that the suffix -kay on a subordinate predicate is ungrammatical. 
(56)
$\begin{array}{llll}\text { a. } & \text { jayna } & {[n-o s} & e<l a \sim>l a:-w a=\emptyset \text {-- } u s] \\ \text { DSC } & \text { OBL-ART.N.PST } & \text { leave_behind }<\mathrm{INV} \sim>=1 \mathrm{SG}-\mathrm{SM} . \mathrm{AB}\end{array}$
it joy-chet tijka:rim
1INTR go-R/R work
'When he left me I went to work.'
b. * [n-os ela-kay-wa= $\emptyset$--us]
OBL-ART.N.PST leave_behind-INV-EVENT=1SG--3M.AB
[BAS tx 011]

[e]

On complex verbal bases that are marked as direct by the base-internal affix $-a-$, this affix is retained in the subordinate form, as shown in (57). Inverse marking, however, is dropped with these bases, as shown by (58).

$\begin{array}{lll}\text { nokwa } & t & \text { joy-chet [n-as } \\ \text { right_now } & \text { 1INTR } & \text { go-R/R } \quad \text { OBL-ART.N }\end{array}$

ken $\langle a>p a:-w a=\emptyset$--sne]

tell $<\mathrm{DR}>$-EVENT $=1 \mathrm{SG}-\mathrm{-}$ F.AB

'Right now I'll go in order to tell her.' [EAO In between 120]

\begin{tabular}{lll} 
jankwa $=u s$ & \multicolumn{1}{c}{ [n-os } & kempa -wa $=y^{\prime}$ 'i] \\
said_thing=3M.AB & OBL-ART.N.PST & inform-EVENT=1PL \\
$n$-os & ima:yoj & \\
OBL-ART.N.PST & morning &
\end{tabular}

'He said, as [he] told us in the morning ...' [JMH Perro II 048]

However, an unmarked subordinate predicate can be identified as bivalent inverse when it occurs with two argument expressions: in (59), both arguments are overtly expressed as bound pronouns.

$$
\begin{array}{llll}
\text { bo } & \text { [os } & \text { kay-poj-wa=y'ti--kisne } & \text { jayna] } \\
\text { REAS } & \text { ART.N.PST } & \text { eat-CAUS-EVENT=1PL--OBV.3F.AB } & \text { DSC } \\
\text { '... so that she could give us food then.' [EAO In between 206] }
\end{array}
$$

When OBV is not overtly expressed, as in (58), the bases of these subordinate predicates look like intransitive bases, like those in (50)-(52) above, and the inverse interpretation is only triggered by the context. In the following example, in contrast, the subordinate predicate dummewa has to be interpreted as reciprocal, because the text is about how two people met, and not about how they were met by someone else:
(60)

$\begin{array}{llll}\text { [n-os } & \text { rey } & \text { jayna } & \begin{array}{l}\text { dumme-wa }=i s] \\ \text { encounter-EVENT=3PL.AB }\end{array}\end{array}$
'when they met' (not: "when he/she/it/they met them")

[HRR tx 183] 
In the domain of voice marking, then, we see that certain categories are not overtly distinguished in subordinate phrases, while they are in main clauses. Most importantly, the inverse is not overtly marked on certain subordinate verbs: this shows that unlike main-clause predicates, valence is not overtly marked on all subordinate predicates.

This raises the issue of whether subordinate predicates should be seen as derived from voice-marked forms from which the voice markers are dropped, or whether it should be assumed that voice marking developed in parallel or perhaps later than the subordinate derivation. This question is the same as the one concerning the subordinate derivation of nouns by means of the suffix -wa (see (33) above): is the action verbalizer -tik dropped as a consequence of the subordinate derivation, or is the subordinate predicate formed directly on the basis of the noun? The fact that the inverse is not overtly marked on certain bases means that at least in subordinate phrases, inverse predicates are closer to monovalent ones than direct predicates. It may also be a hint that diachronically, inverse marking developed later than direct marking. In any case, voice is underspecified in subordinate phrases.

\subsection{The article in subordinate phrases}

Subordinate phrases are marked for an important "verbal" feature that main clauses lack: tense. As was illustrated in 3 above, in RPs referring to concrete entitites, the article indicates presence, absence, and ceased existence of the referent. With subordinate phrases, the article does not indicate presence or absence, but has an exclusively temporal interpretation, including a third temporal category. The presential article indicates nonpast, the absential article indicates that the event took place on the same day, but before the moment of speaking, and the past article indicates that the event occurred before the day of speaking. The examples in (61), offered spontaneously during elicitation, illustrate this contrast nicely.

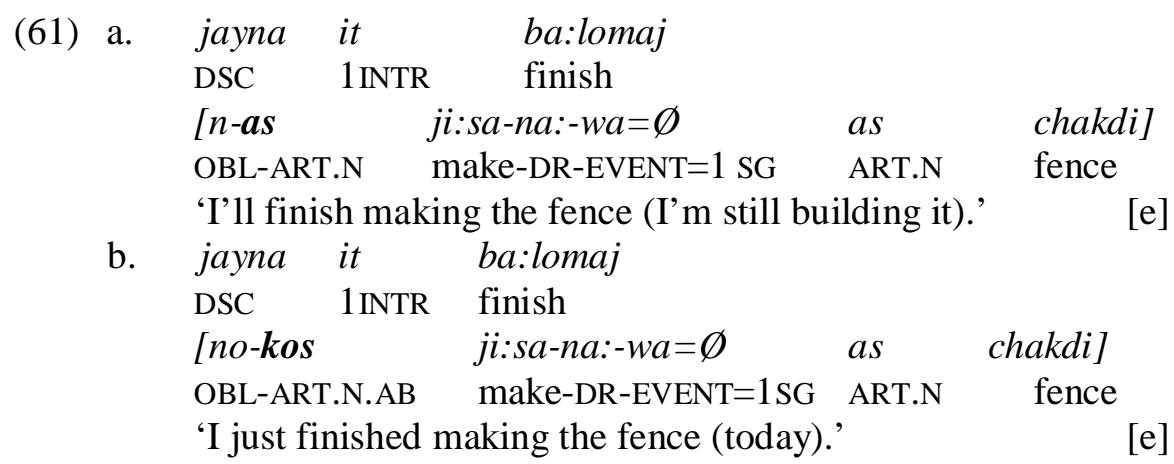



c. jayna it ba:lomaj
DSC 1INTR finish
[n-os ji:sa-na:-wa $\varnothing$ as chakdi]
OBL-ART.N.PST make-DR-EVENT=1SG ART.N fence
'I finished making the fence (before today).' [e]

The three-way temporal distinction, which does not exist with RPs with concrete referents, can be explained by the fact that subordinate phrases refer to concepts that do not have a spatial location and that are not timestable. Therefore, the article can be employed unambiguously for temporal instead of spatial deixis, the absential article introducing an additional temporal category.

At the same time, there is a direct parallel with RPs denoting concrete entities, whose referent must have ceased to exist in order to be referred to with the past article. In the case of times and situations, the absential and past forms can be used only when the situation is concluded. A situation that has started in the past but is continuing in the present is always referred to with the presential article:

$\begin{array}{lcccc}\text { jayna jaysot sota'-sema:na } & \text { [as } & \text { ya:lowe-wa }=y^{\prime} t i \\ \text { DSC seem one-week } & & \text { ART.N } & \text { drink-EVENT=1PL } \\ n \text {-as } & \text { cho:'es } & d i & \text { to:mi] } & \\ \text { OBL-ART.N dirty } & \text { REL } & \text { water } & \end{array}$

'It has been for about one week that we have been drinking dirty water.'

[EAO Agua sucia 001]

The most interesting feature, which could be observed in many of the above examples, is that the tense encoded by the article in a subordinate phrase has scope over the main-clause predicate. This is an effect of implicature, which can only be cancelled when the main clause contains an element that contradicts the temporal information given by the article. In (63), for instance, the imperative form of the main-clause predicate implies nonpast tense; therefore, the past-tense article marks the temporal location of the subordinate event only.
ajlomaj-ti
Cos
naye- $w a=n]$
tell_about-IMP.DR ART.N.PST marry-EVENT=2
'Tell (her) of how you married!' (lit.: 'Narrate your past- marrying!")
[EAO spont.]

The article is the main marker of tense in a text, particularly because of the frequency of subordinate phrases, which denote inherently non-time-stable 
concepts. ${ }^{21}$ This is illustrated by the following examples, which are first sentences of past-tense narrative texts. They both contain RPs referring to fixed locations, which, therefore, contain the presential article (cf. Haude 2004). Therefore, temporal reference is established exclusively by the subordinate phrases.

(64)

\begin{tabular}{|c|c|c|c|c|c|}
\hline $\begin{array}{l}{[n-o s} \\
\text { OBL-A }\end{array}$ & T N.PST & $\begin{array}{ll}\text { ney } & \text { jayna } \\
\text { here }^{22} & \text { DSC }\end{array}$ & $\begin{array}{l}\text { joy-wa }=n \\
\text { go-EVENT }=2 \mathrm{SG}\end{array}$ & $\begin{array}{l}\text { ulkwat } \\
\text { PRO } 2 \mathrm{~S}\end{array}$ & \\
\hline jayna & $t$ & $j i<w a:>w a$ & neyru & Santa & Ana \\
\hline DSC & 1INTR & come $\langle\mathrm{MD} \sim>$ & OBL-ART.N & Santa & Ana \\
\hline
\end{tabular}

(65)

$\begin{array}{llll}\text { kaw-ra } & \text { [os } & \text { iloni-wa=y'ti], } & \text { as-na=y'ti } \\ \text { much-BE.NTR } & \text { ART.N.PST } & \text { walk-EVENT=1PL } & \text { sit-LOC=1PL }\end{array}$

n-as Ma:to

OBL-ART.N Mato

'We walked a lot, we lived by the Mato (river).' (lit.: "A lot (is) our past-walking, we live by the Mato.") [EGA Cazando 001]

Tense particles can occur inside subordinate phrases as well (see Haude $2010 b)$. Consider the following examples with the past particle $l a$ ' (66) and the future particle nokowa (67). The corresponding temporal interpretation of the main clause is again an implicature effect.

$$
\begin{aligned}
& \text { ka:'i, [n-os rey la' sa:waro], [n-os } \\
& \text { no OBL-ART.N.PST MOD ANT Saturday OBL-ART.N.PST } \\
& \text { la' rey pul-et-wa=y'ti], kas rey } \\
& \text { ANT again sweep-AGT-EVENT=1PL is_not MOD } \\
& \text { baw-ra-wa }=y^{\prime} d i \\
& \text { pay-BE.NTR-EVENT=1PL }
\end{aligned}
$$

'No, last Saturday, when we swept last time, again we weren't paid, you know.'

[EGA Dialogue 006]

$\begin{array}{llcl}\text { [n-as } & \text { nokowa } & \text { jiwa-wa=us } & n e y=s \\ \text { OBL-ART.N } & \text { right_now } & \text { come-EVENT=3M.AB } & \text { here=DET } \\ \text { agosto] } & \text { jayna } & n-a^{\prime} k o & \text { kempa: }-w a=\emptyset--u s \\ \text { August } & \text { DSC } & \text { OBL-PRO.N } & \text { inform-EVENT=1SG--3M.AB }\end{array}$

'When he comes now in August, that will be when he tells me.'

21 They share this property with expressions denoting times (e.g. 'day', 'year') (Haude 2004).

${ }^{22}$ When occurring inside a RP, ney marks definiteness (Haude 2006: 142f.). 
[EAO Patrona 043]

Thus, the same elements that serve for temporal reference in main clauses occur in subordinate phrases; there is no reduced temporal information in subordination. In addition, due to the fact that in Movima, tense is a feature of referential elements, subordinate phrases provide consistent temporal information, a feature that main-clause predicates lack.

\section{Conclusion}

From the findings presented in the previous sections, I conclude that subordinate phrases in Movima encode more distinct categories commonly thought of as "verbal" than main-clause predicates. The main differences are listed in Table 2, with +/- symbols indicating roughly the presence or absence of certain features. It can be seen that only in the domain of voice marking, subordinate phrases contain less information than main-clause predicates.

@@ Insert Table 2 here

One reason for the high degree of overt encoding of information on person, aspect and tense in subordinate phrases is that many features that are generally considered to be typical of predication, are associated with reference in Movima. The obligatory encoding of the argument of a subordinate intransitive clause is due to the fact that subordinate clauses have the form of obligatorily possessed RPs, and possessors are encoded in the same way as PROX. ${ }^{23}$

The overt encoding of lexical aspect is due to different strategies of subordinate derivation, either by suffixation of $-w a$ or by reduplication. These are likely to depend on the word class that constitutes the predicate, and verbal and nominal predicates have the different properties of denoting situations and entities, respectively. However, on words that occupy an intermediate state between nouns and verbs, such as some adjectives, there is a choice between the two types of derivation, which marks lexical aspect. This is evidence against the assumption that the choice of the derivational morpheme is lexically conditioned.

The encoding of temporal deixis is not a morphological feature of verbs, but a property of referential elements (in particular, articles) in Movima. The fact that subordinate clauses have the form of referential phrases

${ }^{23}$ In fact, rather than asking whether possessor encoding in subordinate clauses can be compared to argument encoding in main clauses, it should be questioned whether PROX in main clauses is a syntactic argument at all, and not a phrasal modifier as well (cf. Haude 2010a). 
explains why tense marking is consistently marked on subordinate, but not on main clauses. Furthermore, due to the fact that subordinate predicates denote not concrete entities, but states and events, the article does not encode spatial deixis in subordinate phrases and can make more finegrained temporal distinctions than with underived nouns.

Finally, we saw that the argument structure of subordinate predicates is basically the same as that of main-clause predicates: the referentially higherranking participant in a two-participant event is encoded like a possessor and the lower-ranking one like the argument of an intransitive main clause. However, the argument of an intransitive subordinate clause is also encoded like a possessor, which leads to a reversed alignment split: it aligns with the actor of a direct and the undergoer in an inverse clauses.

Furthermore, on the semantic side, we find that subordinate predicates denote situations, whereas RPs containing underived verbs refer to participants in situations. Thus, when considered from a typological perspective, we find a paradoxical situation in Movima: subordination is carried out in the form of a referential phrase, which, together with morphological marking of the predicate, can be considered an subordination-by-nominalization strategy. However, with respect to the categories encoded, the result of this operation is more verblike than an underived verb, an effect that can largely be ascribed to the peculiar properties of Movima referential phrases.

\section{References}

Comrie, Bernard and Sandra A. Thompson. 1985. Lexical Nominalization. In: Language Typology and Syntactic Description. Vol. III: Grammatical Categories and the Lexicon, Timothy Shopen (ed), 349398. Cambridge: Cambridge University Press. Second edition.

Cristofaro, Sonia. 2003. Subordination. Oxford: Oxford University Press.

Croft, William. 2003. Typology and Universals (2nd edition). Cambridge: Cambridge University Press.

Haude, Katharina. 2004. Nominal Tense Marking in Movima: Nominal or Clausal Scope? In: Linguistics in the Netherlands 2004, Leonie Cornips and Jenny Doetjes (eds), 80-90. Amsterdam/Philadelphia: Benjamins.

----. 2006. A Grammar of Movima. Doctoral thesis, Radboud University Nijmegen (http://webdoc.ubn.ru.nl/mono/h/haude_k/gramofmo.pdf)

----. 2009a. "Reference and Predication in Movima". In New Challenges in Typology 2: Transcending the Borders and Refining the Distinctions, Patience Epps and Alexandre Arkhipov (eds), 323-342. Berlin/New York: Mouton de Gruyter.

----. 2009b. Hierarchical alignment in Movima. International Journal of American Linguistics, 513-532. 
----. To appear. First and second person in Movima. International Journal of American Linguistics .

----. 2010a. The intransitive basis of Movima clause structure. In Ergativity in Amazonia, Spike Gildea and Francesc Queixalós (eds), 287-317. Amsterdam/Philadelphia: Benjamins.

----. 2010b. 'She kisses her late husband = she kissed her husband': nominal tense in Movima. Rara and Rarissima. Cysouw, Michael and Jan Wohlgemuth (eds), xx-xx. Berlin/New York: Mouton de Gruyter.

Horie, Kaoru. 2001. Complement clauses. In: Language Typology and Language Universals. An International Handbook. Vol. 2. Martin Haspelmath et al. (eds) 979-993. Berlin/New York: Mouton de Gruyter.

Nikolaeva, Irina (ed.). 2007. Introduction. In: Finiteness, Irina Nikolaeva (ed), 1-19. Oxford: Oxford University Press.

Noonan, Michael. 2007. Complementation. In: Language Typology and Syntactic Description, Vol. II: Complex Constructions (2nd edition), Timothy Shopen (ed), 52-15. Cambridge: Cambridge University Press.

Payne, Thomas E. 1997. Describing Morphosyntax. A guide for field linguists. Cambridge: CUP.

Schachter, Paul. 1985. Parts-of-speech systems. In: Language Typology and Syntactic Description, Vol. 1: Clause Structure, Timothy Shopen (ed), 3-61. Cambrigde: Cambridge University Press.

\section{Symbols and abbreviations}

$\sim$ reduplication, $<>$ infixation, = internal cliticization, -- external cliticization.

$1=$ first person; $2=$ second person; $3=$ third person; $\mathrm{AB}=$ absential; $\mathrm{ABSTR}=$ abstract nominal; $\mathrm{AG}=$ agent nominalization; $\mathrm{AGT}=$ agentive voice; $\mathrm{ANT}=$ anterior; $\mathrm{ART}=$ article; $\mathrm{BE}=$ bound nominal element; $\mathrm{BR}=$ bound root; CAUS=causative; $\quad \mathrm{CO}=$ co-participant; $\quad \mathrm{CSQ}=$ consequence $\quad \mathrm{D}=$ dummy; DET=determiner; $\quad \mathrm{DR}=$ direct; $\quad \mathrm{DSC}=$ discontinuous; $\quad$ DUR=durative; $\mathrm{EV}=$ evidential; EVENT=event subordinator; $\mathrm{F}=$ feminine; HYP=hypothetical; $\mathrm{IMM}=$ immediate past; IMP=imperative; INAL=inalienable; INTR=intransitive; $\mathrm{INV}=$ inverse; LV=linking nasal; LOC=locative verbalization; LV=linking vowel; $\mathrm{M}=$ masculine; $\mathrm{MD}=$ middle; $\mathrm{MOD}=$ modal; $\mathrm{N}=$ neuter; $\mathrm{NEG} . \mathrm{SUB}=$ subordinate negation; NST=nonstanding; NTR=neutral; $\quad \mathrm{OBL}=$ oblique; $\mathrm{OBV}=$ obviative; $\mathrm{PST}=$ past tense; $\mathrm{PL}=$ plural; $\mathrm{POSS}=$ possessive; $\mathrm{PRC}=$ process verbalization; $\mathrm{PRO}=$ free pronoun; $\mathrm{R} / \mathrm{R}=$ reflexive/reciprocal; REAS=reason; $\mathrm{RED}=$ reduplication; $\mathrm{REL}=$ relativizer; $\mathrm{SG}=$ singular; $\mathrm{STATE}=$ state subordinator; VBZ=action verbalizer. 
Table 1. Articles

\begin{tabular}{l|l|l|l}
\hline & presential/generic & absential & past (ceased to exist) \\
\hline masculine & us & kus & us \\
feminine & i’nes & kinos & isnos \\
neuter & as & kos & os \\
plural & is & kis & is \\
\hline
\end{tabular}

Table 2. Categories encoded in main vs. complement and adverbial clauses

\begin{tabular}{lll}
\hline $\begin{array}{l}\text { Main } \\
\text { clause }\end{array}$ & Category & $\begin{array}{l}\text { Subordinate } \\
\text { clause }\end{array}$ \\
\hline- & $\begin{array}{l}\text { Obligatory encoding of single argument } \\
\text { of intransitive clause }\end{array}$ \\
& $\begin{array}{l}\text { Overt marking of lexical aspect } \\
\text { (event/temporal state vs. existential state) }\end{array}$ \\
& $\begin{array}{l}\text { Consistent tense marking } \\
-\end{array}$ & + \\
+ & Two overt core arguments possible & + \\
+ & Consistent voice marking & - \\
\hline
\end{tabular}

